\title{
Structural influence on atomic hopping and electronic states of Pd-based bulk metallic glasses
}

\author{
X.-P. Tang \\ Department of Physics, University of Nevada, Reno, Nevada 89557 \\ Jörg F. Löffler \\ Laboratory of Metal Physics and Technology, Department of Materials, ETH Zürich, CH-8093 Zürich, \\ Switzerland \\ R. B. Schwarz \\ MS G755, MST-8, Materials Science and Technology Division, Los Alamos National Laboratory, Los \\ Alamos, New Mexico 87545 \\ William L. Johnson \\ W. M. Keck Laboratory, California Institute of Technology, Pasadena, California 91125 \\ Yue $\mathrm{Wu}^{\mathrm{a})}$ \\ Department of Physics and Astronomy and Curriculum in Applied and Materials Sciences, University of \\ North Carolina, Chapel Hill, North Carolina 27599-3255
}

(Received 24 June 2004; accepted 21 December 2004; published online 9 February 2005)

\begin{abstract}
Atomic motion and electronic structures of $\mathrm{Pd}-\mathrm{Ni}-\mathrm{Cu}-\mathrm{P}$ bulk metallic glasses were investigated using ${ }^{31} \mathrm{P}$ nuclear magnetic resonance. The hopping rate of $\mathrm{P}$ atoms was determined by the stimulated echo technique. Significant hopping was observed in all alloys well below the glass transition temperature. Increasing the $\mathrm{Cu}$ content to above 25 at. \% increases $\mathrm{P}$ hopping significantly, consistent with the previous finding that the openness of the structure increases with $\mathrm{Cu}$ content. In contrast, $\mathrm{P}$ hopping is not influenced by changes of local electronic states at $\mathrm{P}$ sites, induced by the substitution of $\mathrm{Ni}$ by $\mathrm{Cu}$. (C) 2005 American Institute of Physics. [DOI: $10.1063 / 1.1866217]$
\end{abstract}

The discovery of bulk metallic glasses (BMG) has stimulated intensive research on the understanding of the glass forming ability (GFA) of metallic systems. ${ }^{1,2}$ Since diffusion is related to factors controlling the GFA such as local topological constraints and packing efficiency, ${ }^{3,4}$ the study of diffusion is important for the understanding of GFA and the nature of glass transition. ${ }^{5}$ Previously, beryllium diffusion in $\mathrm{Zr}_{41.2} \mathrm{Ti}_{13.8} \mathrm{Cu}_{12.5} \mathrm{Ni}_{10} \mathrm{Be}_{22.5}$ (Vit1) and $\mathrm{Zr}_{46.75} \mathrm{Ti}_{8.25} \mathrm{Cu}_{7.5} \mathrm{Ni}_{10} \mathrm{Be}_{27.5}$ (Vit4) BMGs was investigated and two beryllium diffusion mechanisms were identified: one involves single-atom hopping and the other involves the collective motion of groups of atoms. ${ }^{6,7}$ It revealed that beryllium hopping is present in both the glassy and supercooled liquid states and the Arrhenius plot of the hopping rate follows a straight line across the glass transition temperature $T_{g}$ with no change of the activation energy. This demonstrates that the observed increase in the apparent activation energy of beryllium diffusion near $T_{g}$ arises simply from the stronger temperature dependence of the collective motion contribution as compared to that of single-atom hopping. ${ }^{6,8}$ Since the same beryllium hopping is observed in the glassy state and in the supercooled liquid above $T_{g}$ where structural relaxation is complete, beryllium hopping is believed to be an intrinsic property of the glassy structures of Vit1 and Vit4. The measurement of small constituent atom hopping is sensitive and could provide valuable insights into why certain alloys with certain compositions possess high GFA. The importance of such study is emphasized by the fact that the

\footnotetext{
a) Author to whom correspondence should be addressed; electronic mail:
} yuewu@physics.unc.edu presence of constituent small atoms is crucial for the GFA of BMG due to the requirement of packing efficiency and topological constraints. ${ }^{3,4}$

$\mathrm{Pd}_{40} \mathrm{Cu}_{x} \mathrm{Ni}_{40-x} \mathrm{P}_{20}$ alloys are also excellent glass formers. Shen et al. found that the molar volume of bulk $\mathrm{Pd}_{40} \mathrm{Cu}_{x} \mathrm{Ni}_{40-x} \mathrm{P}_{20}$ glasses increases rapidly when the copper content exceeds $x=10$ at. \%. ${ }^{9}$ Such increased openness of the glassy structure could affect the hopping motion of small atoms such as P. Here we present ${ }^{31} \mathrm{P}$ NMR measurements of $\mathrm{P}$ hopping in five $\mathrm{Pd}-\mathrm{Ni}-\mathrm{P}$ and $\mathrm{Pd}-\mathrm{Cu}-\mathrm{Ni}-\mathrm{P}$ bulk metallic glasses. A significant hopping rate was observed below $T_{g}$ in all the alloys. It was found that increasing the $\mathrm{Cu}$ content indeed enhances the $\mathrm{P}$ hopping rate. In addition, ${ }^{31} \mathrm{P}$ NMR was used to characterize the electronic density of states at the Fermi level, providing information on its relationship with phosphorus hopping.

Five BMGs were used in this study: $\mathrm{Pd}_{40} \mathrm{Ni}_{40} \mathrm{P}_{20}$ (S1), $\mathrm{Pd}_{40} \mathrm{Cu}_{30} \mathrm{Ni}_{10} \mathrm{P}_{20}(\mathrm{~S} 2), \mathrm{Pd}_{43} \mathrm{Cu}_{27} \mathrm{Ni}_{10} \mathrm{P}_{20}(\mathrm{~S} 3), \mathrm{Pd}_{47} \mathrm{Cu}_{25} \mathrm{Ni}_{9} \mathrm{P}_{19}$ (S4), and $\mathrm{Pd}_{41.75} \mathrm{Cu}_{41.75} \mathrm{P}_{16.5}$ (S5). Their synthesis was described previously. ${ }^{10,11}$ NMR measurements were conducted with a pulsed spectrometer at a magnetic field of $9.4 \mathrm{~T}$ as described elsewhere. ${ }^{7,12}$ Figure 1 shows the ${ }^{31} \mathrm{P}$ NMR spectra of glassy $\mathrm{Pd}_{40} \mathrm{Ni}_{40} \mathrm{P}_{20}$ (S1) and glassy $\mathrm{Pd}_{43} \mathrm{Cu}_{27} \mathrm{Ni}_{10} \mathrm{P}_{20}$ (S3). The ${ }^{31} \mathrm{P}$ spectra of $\mathrm{S} 2, \mathrm{~S} 4$, and $\mathrm{S} 5$ are identical to that of glassy $\mathrm{Pd}_{43} \mathrm{Cu}_{27} \mathrm{Ni}_{10} \mathrm{P}_{20}$. The spectral linewidth at the full width at half maximum is about $112.5 \mathrm{kHz}$ for glassy $\mathrm{Pd}_{40} \mathrm{Ni}_{40} \mathrm{P}_{20}$ and $94.5 \mathrm{kHz}$ for glassy $\mathrm{Pd}_{43} \mathrm{Cu}_{27} \mathrm{Ni}_{10} \mathrm{P}_{20}$. It is interesting to note that the ${ }^{31} \mathrm{P}$ spectrum of glassy $\mathrm{Pd}_{43} \mathrm{Cu}_{27} \mathrm{Ni}_{10} \mathrm{P}_{20}$ overlaps with that of glassy $\mathrm{Pd}_{40} \mathrm{Ni}_{40} \mathrm{P}_{20}$, if the frequency axis of the latter is scaled by a factor of $1 / 1.31$ (Fig. 1). 


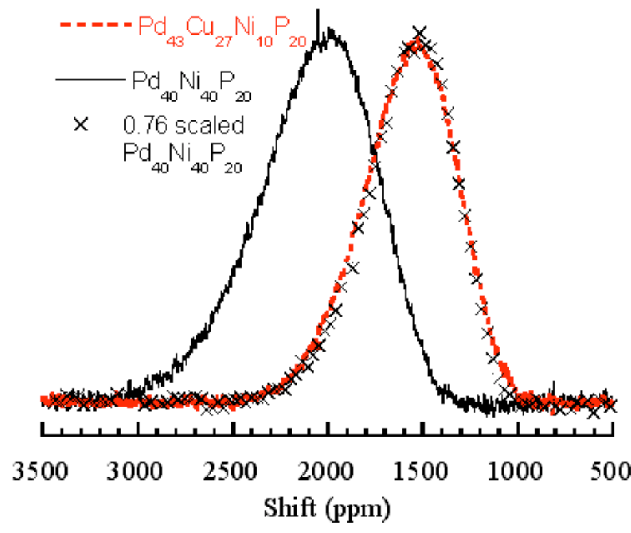

FIG. 1. (Color online) The ${ }^{31} \mathrm{P}$ spectra (obtained with Hahn echo) of glassy $\mathrm{Pd}_{40} \mathrm{Ni}_{40} \mathrm{P}_{20}(\mathrm{~S} 1)$ and $\mathrm{Pd}_{43} \mathrm{Cu}_{27} \mathrm{Ni}_{10} \mathrm{P}_{20}(\mathrm{~S} 3)$ at $9.4 \mathrm{~T}$ and $290 \mathrm{~K}$. The shift reference is ${ }^{31} \mathrm{P}$ in $85 \% \mathrm{H}_{3} \mathrm{PO}_{4}$ in $\mathrm{H}_{2} \mathrm{O}$.

The resonance frequency in metals is determined by the Knight shift given by ${ }^{13}$

$$
K=\frac{8 \pi}{3}\left\langle|\psi(0)|^{2}\right\rangle_{E_{F}} V \chi_{\text {Pauli }},
$$

where $\left\langle|\psi(0)|^{2}\right\rangle_{E_{F}}$ is the density of the electron wave function at the nucleus averaged over all states at the Fermi level $E_{F}$ and the entire electron wave function $\left\langle|\psi(\mathbf{r})|^{2}\right\rangle$ is normalized over the volume $V . \chi_{\text {Pauli }}$ is the Pauli paramagnetic susceptibility per unit volume. Assuming noninteracting electrons, $\chi_{\text {Pauli }}$ is given by $\chi_{\text {Pauli }}=2 \mu_{B}^{2} g\left(E_{F}\right)$ where $\mu_{B}$ is the Bohr magneton and $g\left(E_{F}\right)$ is the density of states per unit volume at the Fermi level (for a single spin orientation). The observed ${ }^{31} \mathrm{P}$ spectra in Fig. 1 indicate that $\left\langle|\psi(0)|^{2}\right\rangle_{E_{F}} V g\left(E_{F}\right)$ in glassy $\mathrm{Pd}_{40} \mathrm{Ni}_{40} \mathrm{P}_{20}$ (S1) is larger than that in the $\mathrm{Cu}$ containing samples by a factor of 1.31 . Since the entire spectrum of S1 overlaps with that of S3 after frequency scaling, the line broadening is most likely due to the Knight shift distribution, predominantly anisotropic Knight shift distribution. ${ }^{12}$ Such anisotropic shift distribution originates from the variation of the local structural configuration with respect to the direction of the external magnetic field.

The interaction that gives rise to the Knight shift also determines the nuclear spin-lattice relaxation rate $1 / T_{1}$ given by ${ }^{13}$

$$
\frac{1}{T_{1} T}=\frac{64}{9} k_{B} \pi^{3} \hbar^{3} \gamma_{e}^{2} \gamma_{n}^{2}\left[\left\langle|\psi(0)|^{2}\right\rangle_{E_{F}} V g\left(E_{F}\right)\right]^{2},
$$

where $\gamma_{e}=2 \mu_{B} / \hbar=1.76 \times 10^{11} \mathrm{~Hz} / \mathrm{T}$ is the electron gyromagnetic ratio, $\gamma_{n}=1.08 \times 10^{8} \mathrm{~Hz} / \mathrm{T}$ is the ${ }^{31} \mathrm{P}$ nuclear gyromagnetic ratio, and $h=2 \pi \hbar$ and $k_{B}$ are the Planck and Boltzmann constants, respectively. The ${ }^{31} \mathrm{P} 1 / T_{1}$ was measured by the saturation recovery method. The ${ }^{31} \mathrm{P} 1 / T_{1}$ is almost identical in S2, S3, S4, and S5 but is larger in S1. Figure 2 displays $1 / T_{1}$ as a function of temperature $(T) .1 / T_{1}$ is approximately proportional to $T$ up to $500 \mathrm{~K}$ in all samples, consistent with Eq. (2). The fits give $1 / T_{1} T$ $=(1.05 \pm 0.02) \mathrm{s}^{-1} \mathrm{~K}^{-1}$ for $\mathrm{S} 1$ and $1 / T_{1} T$ $=(0.70 \pm 0.05) \mathrm{s}^{-1} \mathrm{~K}^{-1}$ for the other samples. These values, according to Eq. (2), indicate that $\left\langle|\psi(0)|^{2}\right\rangle_{E_{F}} V g\left(E_{F}\right)$ in $\mathrm{S} 1$ is larger than that in S2, S3, S4, and S5 by a factor of 1.22, comparable to the 1.31 factor obtained from the Knight shift. The NMR result is consistent with the previous report (Ref. 9), which suggested a change of short-range order in $\mathrm{Pd}-\mathrm{Cu}-$ Downloaded 14 Dec 2005 to 131.215.225.171. Redistribution subje

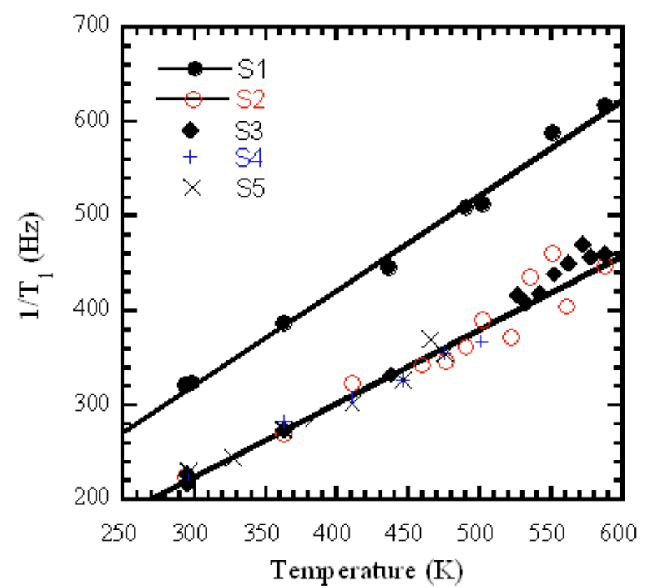

FIG. 2. (Color online) The ${ }^{31} \mathrm{P} 1 / T_{1}$ as a function of temperature for samples S1, S2, S3, S4, and S5. The solid lines are fits of linear temperature dependence of $1 / T_{1}$.

$\mathrm{Ni}-\mathrm{P}$ glasses when the $\mathrm{Cu}$ content exceeds 10 at. $\%$.

The ${ }^{31} \mathrm{P}$ NMR stimulated echo technique, $90_{x}^{\circ}-\tau-90_{y}^{\circ}$ $-t-90^{\circ}-\tau^{\prime}-$, was used to measure the hopping rate of phosphorus. ${ }^{14}$ The typical $90^{\circ}$ pulse used was $1.5 \mu \mathrm{s}, \tau$ $=25 \mu \mathrm{s}, t \gg \tau$, and the signal was detected during the time interval $\tau^{\prime}$. After the third $90^{\circ}$ pulse a stimulated echo forms at $\tau^{\prime}=\tau$. Under the condition $t>T_{2}$, where the spin-spin relaxation time $T_{2}$ is on the order of $500 \mu \mathrm{s}$, the stimulatedecho amplitude is proportional to the ensemble-averaged single-particle correlation function $f(t)$ $=\left\langle\sin (\omega \tau) \sin \left(\omega^{\prime} \tau^{\prime}\right)\right\rangle \exp \left(-t / T_{1}\right)$ where $\omega$ and $\omega^{\prime}$ are proportional to the local magnetic field experienced by a given spin during the time intervals $\tau$ and $\tau^{\prime}$, respectively. If the local environment of any given spin does not change during the time interval $t, \omega$ and $\omega^{\prime}$ will be the same and the correlation function $f(t)$ will decay only through the spin-lattice relaxation given by the factor $\exp \left(-t / T_{1}\right)$. If the probability of atomic hopping over the time interval $t$ is significant, $\omega$ experienced by a given spin is likely to change during the time interval $t$. This will cause $\left\langle\sin (\omega \tau) \sin \left(\omega^{\prime} \tau^{\prime}\right)\right\rangle$ to decay. ${ }^{7,14}$ For a stochastic process with the rate of atom hopping given by $\Omega$ in an amorphous system, $\left\langle\sin (\omega \tau) \sin \left(\omega^{\prime} \tau^{\prime}\right)\right\rangle$ decays as $\exp (-\Omega t)$. Thus, $f(t)$ is proportional to $\exp \left[-\left(\Omega+1 / T_{1}\right) t\right]$. We measured the amplitude of the stimulated echo as a function of $t$. The decay of the amplitude is exponential. From

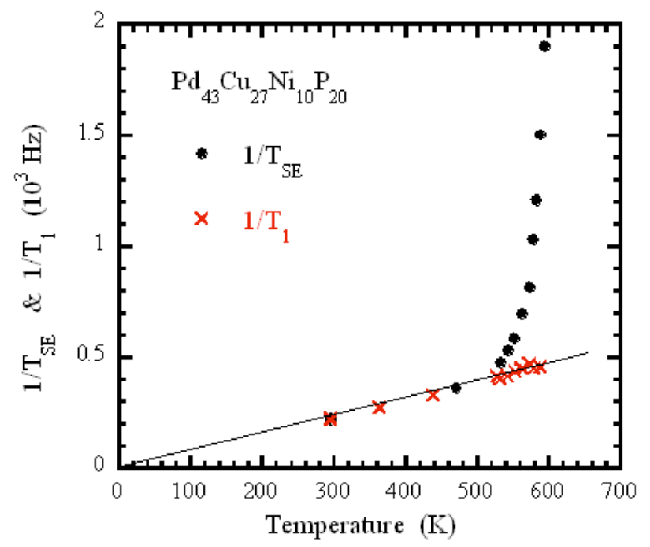

FIG. 3. (Color online) The ${ }^{31} \mathrm{P} 1 / T_{1}$ and $1 / T_{\mathrm{SE}}$ as a function of temperature for sample $\mathrm{Pd}_{43} \mathrm{Cu}_{27} \mathrm{Ni}_{10} \mathrm{P}_{20}(\mathrm{~S} 3)$. The solid line is a fit of the linear temperature dependence of $1 / T_{1}$. 


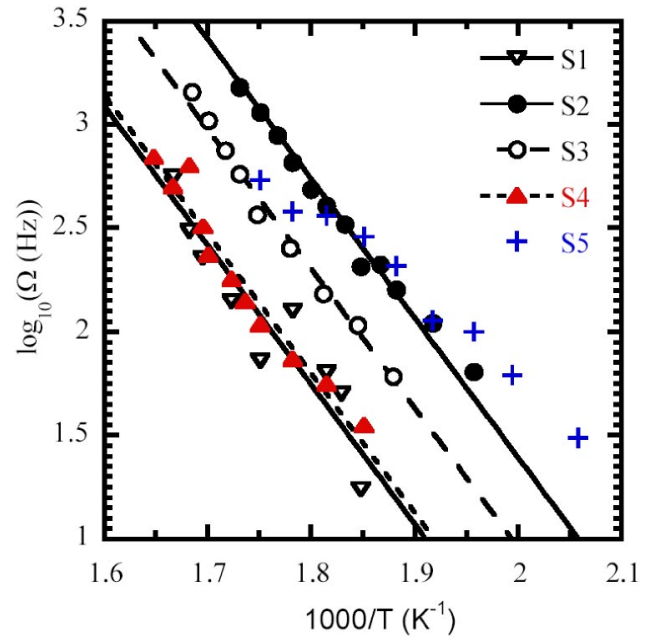

FIG. 4. (Color online) The temperature dependence of atomic jump rates $\Omega$ in glassy $\mathrm{Pd}_{40} \mathrm{Ni}_{40} \mathrm{P}_{20}(\mathrm{~S} 1), \mathrm{Pd}_{40} \mathrm{Cu}_{30} \mathrm{Ni}_{10} \mathrm{P}_{20}$ (S2), $\mathrm{Pd}_{43} \mathrm{Cu}_{27} \mathrm{Ni}_{10} \mathrm{P}_{20}$ (S3), $\mathrm{Pd}_{47} \mathrm{Cu}_{25} \mathrm{Ni}_{9} \mathrm{P}_{19}$ (S4), and $\mathrm{Pd}_{41.75} \mathrm{Cu}_{41.75} \mathrm{P}_{16.5}$ (S5). The straight lines are Arrhenius fits of $\Omega$.

this decay $1 / T_{\mathrm{SE}} \equiv \Omega+1 / T_{1}$ is determined. Since $1 / T_{1}$ is determined by the saturation recovery method, $\Omega$ is then determined. Figure 3 shows the measured $1 / T_{\mathrm{SE}}$ and $1 / T_{1}$ for sample S3. It is clear that $1 / T_{\mathrm{SE}}$ is identical to $1 / T_{1}$ at low temperatures but increases rapidly above $500 \mathrm{~K}$ due to the increase of $\Omega$. Annealing at temperature slightly below $T_{g}$ (all around $580 \mathrm{~K}$ ) does not affect the measured hopping rate. Figure 4 is an Arrhenius plot of the measured $\Omega$ versus $1000 / T$ for the five samples. All $\Omega$ curves indicate an activated process: $\Omega(T)=\Omega_{0} \exp \left(-E_{a} / k_{B} T\right)$. For S1, S2, S3, and $\mathrm{S} 4$, the fitted $E_{a}$ is $(1.3 \pm 0.1) \mathrm{eV}$ and the respectively fitted prefactor $\Omega_{0}$ is about $7.3 \times 10^{13}, 7.2 \times 10^{14}, 2.6 \times 10^{14}$, and $8.3 \times 10^{13} \mathrm{~s}^{-1}$. For S5, the fitting yields $E_{a}=(0.8 \pm 0.2) \mathrm{eV}$ and $\Omega_{0}=6.8 \times 10^{9} \mathrm{~s}^{-1}$. The comparison of the results for $\mathrm{Pd}_{41.75} \mathrm{Cu}_{41.75} \mathrm{P}_{16.5} \quad(\mathrm{~S} 5), \quad \mathrm{Pd}_{40} \mathrm{Cu}_{30} \mathrm{Ni}_{10} \mathrm{P}_{20} \quad$ (S2), and $\mathrm{Pd}_{40} \mathrm{Ni}_{40} \mathrm{P}_{20}$ (S1) in Fig. 4, suggests that a substitution of $\mathrm{Cu}$ by Ni reduces the $\mathrm{P}$ hopping rate. Furthermore, the comparison of the results for $\mathrm{Pd}_{40} \mathrm{Cu}_{30} \mathrm{Ni}_{10} \mathrm{P}_{20}(\mathrm{~S} 2), \mathrm{Pd}_{43} \mathrm{Cu}_{27} \mathrm{Ni}_{10} \mathrm{P}_{20}$ (S3), and $\mathrm{Pd}_{47} \mathrm{Cu}_{25} \mathrm{Ni}_{9} \mathrm{P}_{19}$ (S4) in Fig. 4, suggests that a substitution of $\mathrm{Cu}$ by $\mathrm{Pd}$ also reduces the $\mathrm{P}$ hopping rate. These results indicate a significant enhancement of the P hopping when the $\mathrm{Cu}$ content exceeds 25 at. \%.

Previous studies on a series of metallic glasses $\mathrm{Pd}_{40} \mathrm{Cu}_{x} \mathrm{Ni}_{40-x} \mathrm{P}_{20}$ showed that the coordination number around $\mathrm{P}$ atoms decreases upon substitution of $\mathrm{Ni}$ by $\mathrm{Cu}^{15} \mathrm{~A}$ significant difference was also found in the electronic structure between $\mathrm{Pd}-\mathrm{Ni}-\mathrm{P}$ and $\mathrm{Pd}-\mathrm{Cu}-\mathrm{P} .{ }^{16,17}$ Furthermore, a molar volume measurement of glassy $\mathrm{Pd}_{40} \mathrm{Cu}_{x} \mathrm{Ni}_{40-x} \mathrm{P}_{20}$ showed ${ }^{9}$ that the rate of molar volume increase versus $x$ is $0.57 \mathrm{~cm}^{3} /$ (mole atoms) for $x<10$ whereas it is $0.93 \mathrm{~cm}^{3} /$ (mole atoms) for $x \geqslant 10$. The molar volume increase versus $x$ above $x=10$ cannot be attributed simply to the size difference between $\mathrm{Cu}$ and $\mathrm{Ni}$. This indicates that a structural change occurs when the $\mathrm{Ni}$ substitution by $\mathrm{Cu}$ reaches $x=10$. This is consistent with the current NMR result which shows that the density of states at the Fermi level is
20\%-30\% larger in $\mathrm{Pd}_{40} \mathrm{Ni}_{40} \mathrm{P}_{20}$ than in $\mathrm{S} 2, \mathrm{~S} 3, \mathrm{~S} 4$, and $\mathrm{S} 5$ where $x \geqslant 25$. Very little change of the density of states at the Fermi level is observable by NMR above $x=25$. In contrast, the hopping rate measurement shows that changes occur above $x=25$ whereas very little change occurs below $x=25$. This suggests that the $\mathrm{P}$ hopping is correlated with the openness of the structure (above 25 at. \% $\mathrm{Cu}$ ) whereas the correlation with the electronic structure is weak in current systems. Finally, it is important to note that although the measured single-atom hopping is one order of magnitude slower in $\mathrm{Pd}_{40} \mathrm{Ni}_{40} \mathrm{P}_{20}$ (S1) than in $\mathrm{Pd}_{40} \mathrm{Cu}_{30} \mathrm{Ni}_{10} \mathrm{P}_{20}$ (S2) (see Fig. 3), the reported viscosity is similar in $\mathrm{S}^{18}$ and $\mathrm{S} 2 .{ }^{19,20}$ This shows that single-atom hopping is decoupled from the structural relaxation.

In conclusion, atomic hopping is an intrinsic property of metallic glasses, particularly for small atoms such as $\mathrm{P}$ atoms in glassy $\mathrm{Pd}-\mathrm{Cu}-\mathrm{Ni}-\mathrm{P}$ and $\mathrm{Be}$ atoms in Vit1 and Vit4. The hopping rate of $\mathrm{P}$ depends sensitively on the openness of the intrinsic glassy structure of $\mathrm{Pd}-\mathrm{Ni}-\mathrm{Cu}-\mathrm{P}$. However, $\mathrm{P}$ hopping is not influenced significantly by changes of local electronic states at $\mathrm{P}$ sites induced by the substitution of $\mathrm{Ni}$ by $\mathrm{Cu}$. It remains to be seen how such hopping motion in metallic glasses is related to the Johari-Goldstein $\beta$ relaxation observed in other glassy systems such as polymers. ${ }^{21}$

This work was supported by the US Army Research Office (Grant No. DAAD19-02-1-0225).

${ }^{1}$ T. Zhang, A. Inoue, and T. Masumoto, Mater. Trans., JIM 32, 1005 (1991).

${ }^{2}$ A. Peker and W. L. Johnson, Appl. Phys. Lett. 63, 2342 (1993).

${ }^{3}$ T. Egami, Mater. Trans., JIM 43, 510 (2002).

${ }^{4}$ D. B. Miracle, W. S. Sanders, and O. N. Senkov, Philos. Mag. 83, 2409 (2003).

${ }^{5}$ F. Faupel, W. Frank, H.-P. Macht, H. Mehrer, V. Naundorf, K. Rätzke, H. Schober, S. Sharma, and H. Teichler, Rev. Mod. Phys. 75, 237 (2003).

${ }^{6}$ X.-P. Tang, U. Geyer, R. Busch, W.-L. Johnson, and Y. Wu, Nature (London) 402, 160 (1999).

${ }^{7}$ X.-P. Tang, R. Busch, W. L. Johnson, and Y. Wu, Phys. Rev. Lett. 81, 5358 (1998).

${ }^{8}$ Here we would like to point out that the conclusion of Ref. 6 was sometimes quoted incorrectly in the literature (see Ref. 5, for instance).

${ }^{9}$ T. D. Shen, U. Harms, and R. B. Schwarz, Appl. Phys. Lett. 83, 4512 (2003).

${ }^{10}$ Y. He, T. Shen, and R. B. Schwarz, Metall. Mater. Trans. A 29, 1795 (1998).

${ }^{11}$ J. F. Löffler, J. Schroers, and W. L. Johnson, Appl. Phys. Lett. 77, 681 (2000).

${ }^{12}$ L. Li, J. Schroers, and Y. Wu, Phys. Rev. Lett. 91, 265502 (2003).

${ }^{13}$ J. Winter, Magnetic Resonance in Metals (Clarendon, Oxford, 1971).

${ }^{14}$ E. Rössler and P. Eiermann, J. Chem. Phys. 100, 5237 (1994).

${ }^{15}$ C. Park, M. Saito, Y. Waseda, N. Nishiyama, and A. Inoue, Mater. Trans., JIM 40, 491 (1999).

${ }^{16}$ O. Jin, R. B. Schwarz, F. M. Alamgir, and H. Jain, Mater. Res. Soc. Symp. Proc. 580, 277 (2000).

${ }^{17}$ D. M. C. Nicholson, F. M. Alamgir, H. Jain, D. B. Williams, and R. B. Schwarz, Mater. Res. Soc. Symp. Proc. 754, 425 (2003).

${ }^{18}$ G. Wilde, G. P. Görler, K. Jeropoulos, R. Willnecker, and H. J. Fecht, Mater. Sci. Forum 269-272, 541 (1998).

${ }^{19}$ H. Kato, Y. Kawamura, and A. Inoue, Appl. Phys. Lett. 73, 3665 (1998).

${ }^{20}$ N. Nishiyama and A. Inoue, Acta Mater. 47, 1487 (1999).

${ }^{21}$ G. P. Johari, J. Non-Cryst. Solids 307-310, 317 (2002). 